\title{
Recent developments in Equine palmar foot syndrome: What has changed for the clinician?
}

\author{
Astrid B. M. Rijkenhuizen \\ Department of Equine Sciences, Faculty of Veterinary Medicine, Utrecht University, Utrecht, The Netherlands
}

\begin{abstract}
Summary
The term Equine palmar (plantar) footsyndrome is the result of the 21 st century reassessment of our ideas about navicular disease. Complementary diagnostic imaging techniques such as computed tomography (CT) and magnetic resonance imaging (MRI) also became available, revolutionising the diagnostic process and enabling clinicians to evaluate the navicular bone and surrounding structures from different angles. It became possible to identify different pathological entities causing clinical signs of palmar foot pain. The diversity in pathology and anatomical extent of the disease, as identified using MRI, offers the opportunity to target the treatment plan to the lesion found. The consequences for treatment and prognosis on base of 4 pathological primary entities as the principle source of lameness (tendonitis of the deep digital flexor tendon, desmitis of the collateral ligament of the distal interphalangeal (DIP) joint, desmitis of the impar ligament, Desmitis of the medial straight sesamoidean ligament) will be discussed in which the turn of the century will be hold as a turning point.
\end{abstract}

Keywords: navicular disease, palmar foot pain, navicular bone, diagnostic imaging

\begin{abstract}
Neve Erkenntnisse über das Equine palmar foot-Syndrom des Pferdes: Was ändert sich für den Kliniker?
Der Begriff des "Equine palmar (plantar) footsyndrome" ist das Ergebnis der neveren wissenschaftlichen Überprüfung unserer Vorstellungen über die Podotrochlose. Die modernen ergänzenden bildgebenden Techniken wie Computertomographie und Magnetresonanztomographie haben die Diagnostik revolutioniert und uns in die Lage versetzt, das Strahlbein und dessen umgebende Strukturen aus unterschiedlichen Blick-winkeln zu betrachten und weiter zu erforschen. Auch wurde es möglich, verschiedene pathologische Mechanismen zu identifizieren, welche klinische Anzeichen von palmarem Zehenschmerz verursachen. Die verschiedenen pathologischen und anatomischen Ausdrucksformen der Erkrankung, wie sie insbesondere durch die Magnetresonanztomographie erkennbar wurden, bieten die Chance, die Therapie zielgerichtet auf die erkannte ursächliche Läsion einzusetzen. Der Beitrag diskutiert die daraus folgenden Konsequenzen für Diagnostik und Therapie auf der Grundlage der 4 wichtigen primären Symptomkomplexe als grundsätzliche Lahmheitsursachen: die Tendinitis der tiefen Beugesehne, die Desmitis der Kollateralbänder des Hufgelenks, die Desmitis des Ligamentum impar sowie die Desmitis des mittleren geraden Strahlbeinbandes.
\end{abstract}

Schlüsselwörter: Podotrochlose, Strahlbein, Bursa navicularis, Diagnostik, bildgebende Verfahren

The term Equine palmar (plantar) footsyndrome is the result of the 21 st century reassessment of our ideas about navicular disease. It was not just by the turn of the century, but by a number of researchers who challenged the dogma relating to the response to diagnostic analgesia, which resulted in better understanding of the validity of this approach to diagnosis and, consequently, to a more considered appraisal during clinical examination (Rijkenhuizen 2006). In addition, echographic techniques improved and information on processes occurring inside the hoof became available. Images obtained by nuclear scintigraphy suggested the presence of active processes within the hoof, although the reliability of scintigraphy as a diagnostic tool attracted some criticism.

Complementary diagnostic imaging techniques such as computed tomography (CT) and magnetic resonance imaging (MRI) also became available, revolutionising the diagnostic process and enabling clinicians to evaluate the navicular bone and surrounding structures from different angles. It became possible to identify different pathological entities causing clinical signs of palmar foot pain. Navicular disease is therefore no longer a viable term for all underlying lesions.
The clinical signs fit better under the heading 'palmar foot syndrome' where a definitive diagnosis should become available, after thorough clinical examination and use of complementary diagnostic techniques.

The classical clinical signs of palmar foot syndrome can be the result of changes in:

the bone tissue

- Navicular disease: changes within the navicular bone: oedema, vascular stasis, enlargement of the nutrient foraminae on the distal and proximal borders, cyst-like medullary areas, subchondral bones changes, changes in the flexor surface, fragmentation of the distal border.

- Cystic lesion in the second or third phalanx.

the soft tissue

- Tendonitis of the DDFT at 3 possible locations: the insertion, palmar to the navicular bone or proximal to the navicular bone. The deep distal flexion tendon lesions can be 
divided in core lesions, dorsal (border)lesions, sagittal splits and insertional lesions (Busoni et al. 2005, Mair and Kinns 2005).

- Desmitis of the collateral ligaments, the impar ligament, the distal annular ligament or the straight sesamoideum ligament. The observed lesions can be divided in core lesions, insertional lesions (sometime associated with fragmentation of the bone, sagittal splits, localised at the medial or lateral site.

- Synovitis of the distal interphalangeal (DIP)joint or the navicular bursa.

Combination of the various pathologies occur concurrently, fore instance tendon damage and navicular bone pathology (Dyson et al. 2003, Murray et al. 2006).

But has all these new insights brought us a different clinical approach to horses with the classic clinical signs of "equine palmar syndrome"? Certainly not for all the pathological entities, but for a few it does. On base of 4 pathological primary entities as the principle source of lameness the consequences to diagnosis and treatment will be discussed in which the turn of the century will be hold as a turning point

\section{Primary lesion 1: tendonitis of the deep digital flexor tendon.}

The tendonitis of the deep digital flexor tendon, was always suspected to play a role in the horse with foot pain that has no identifiable radiographic abnormalities of navicular disease (Dyson et al 2003). The clinical history and lameness examination does not reveal any difference of the classical signs of navicular disease. At palpation a pain reaction can be revealed with manual pressure between the hoof bulbs. After a perineural analgesia of the palmar digital nerve a significant improvement in the degree of lameness (>50\%) can observed in about $70 \%$ of cases (Dyson et al. 2003 b, Mair and Kinns 2005). Complete elimination of lameness following this nerve block is observed in only $24 \%$ of the cases (Dyson et al. 2003b). Following a unilateral perineural analgesia of the palmar digital nerve block the lameness can be diminish quite obviously up to about $90 \%$ depending on the site of the lesion. An intra-articular analgesia of the DIP joint or the navicular bursa can in case of tendonitis of the DDFT result in a significant improvement (Dyson and Kidd 1993). From the available studies it can be concluded that pain associated with DDF tendonitis in the digit is not reliably eliminated by apparent desensitization of the palmar aspect of the foot (Mair and Kinns 2005).

Ultrasonography performed via the palmar pastern, bulbs of heel, and through the frog (transcutaneal approach) can give an indication of echogenic changes in the DDFT at the level of the navicular bone and in the hoof. The DDFT proximal to the navicular bone can be visualised quite clearly. Whereas it is difficult to obtain an clear image of the DDFT that curves around the navicular bone because the fibers are not perpendicular to the probe (Grewald et al 2004) it limits its diagnostic value, although changes in size and shape can still be appreciated (Mair and Kinns 2005). However, the value of diagnostic ultrasonography is heavily dependent on the type of equipment available and user-expertise and compared to the MRI ultrasonography as a technique is unreliable in identifying the lesions (Mair and Kinns 2005). The use of the MRI made it possible to identify the DDFT lesions. The tendon lesions can be classified based on their location, extent and MR imaging appearance. The lesion of the DDFT have been found proximal to the navicular bone, at the level of the navicular bone and at its insertion to the third phalanx (Dyson et al. 2003). Focal lesions are usually confined to either the medial or lateral lobes of the DDFT, but occasionally affect both lobes. The fact that most lesions of the distal/insertional parts of the DDFT identified by MRI affect either the medial or lateral lobes would explain why these lesions could not be detected ultrasonographically using the sagittal transcuneal approach (Dyson et al. 2003). Tendon lesions are classified as core lesions, dorsal lesions, dorsal abrasions, sagittal full-thickness splits and parasagittal splits, and insertional lesions (Mair and Kinns 2005, Busoni et al. 2005). In case of a horse with the classical signs of palmar foot syndrome with no identifiable radiographic abnormalities of navicular disease ultrasonography indicate the localisation, whereas the use of the MRI provide us with the exact location and severity of the lesion.

On base of this information the horse can be treated as having a tendonitis: prolonged resting period, training scheme and on base of biomechanical studies orthopaedic shoeing.

Whereas in the past shoeing was advised on empiricism, now it is on base of biomechanical research. Elevation of the heels, as used quite frequently in practice, induces flexion of the interphalangeal joints (Denoix 1999), decreases the tension in the DDFT, reduces the pressure exerted by the deep flexor tendon to the navicular bone (Willemen et al. 1999, Wilson et al. 2001, Scheffer and Back 2001, Schoonover et al. 2005), reduces the load on the forelimbs (Rogers and Back 2003) and reduces stress on, and deformation of, the hoof capsule (Hinterhofer et al. 2000). The heels are supported for a greater proportion of the stride and the wedge tends to increase the weight transferred through the heels, because the point of force has moved towards the heel and the moment of force at the DIP is reduced (Willemen et al. 1999, Scheffer and Back 2001, Schoonover et al. 2005). Raising the heels also leads to increased DIP pressure, as measured in the dorsal pouch, and increased loading of the dorsal aspect of the joint (Viitanen et al. 2003). To relieve this pressure, horses with raised heels tend to lean slightly backwards (Denoix et al.1999).

The effect of raising the heel is helped by rolling the toe to relieve the pressure on the navicular bone. The rationale of this approach is indirectly supported by the finding that delaying the breakover exacerbates stress in the interphalangeal joints (Chateau et al. 2005). Trimming itselfs reduces the duration of landing, resulting in a faster complete foot support during the impact phase of landing; the centre of force moves more quickly to the centre of the foot, which has a positive effect on load distribution in the hoof (Heel et al. 2004). One important point is, that when evaluating the effect of shoeing, an adaptation period of 2-3 weeks is necessary to achieve pain-relief (Schoonover et al. 2005). This should be taken into consideration when a horse is treated.

Besides shoeing it should be considered to treat the patients as having a tendonitis, as for instance a tendonitis of the digital flexor tendons. All the established treatments used for the usual tendonitis could have a surplus value to the more conventional treatment of navicular disease. Certainly the con- 


\section{Orthopädie II - \\ proximale Gliedmaßen \\ und Rücken}

mit Astrid Rijkenhuizen, Peter Stadler und René van Weeren

16.-17. September 2006

Berlin-Brandenburgische Akademie der Wissenschaften

Klinische Lahmheitsuntersuchung

Physiologie und Pathologie des Gelenks

Röntgen- und Ultraschalldiagnostik

Spezielle Erkrankungen der proximalen Gelenke

Fissuren und Frakturen

Ergänzende bildgebende Diagnostik

Funktionelle Anatomie der Wirbelsäule

Spezielle Erkrankungen der HWS, BWS, LWS und Kreuzgelenke

Weichteiltraumatologie, Wund-und Verbandbehandlung

Chirurgische und minimalinvasive Eingriffe Bewertung von Röntgenbefunden im Rahmen der KU

Fehlstellungen in Karpal-und Tarsalgelenk

Kasuistiken

Teilnahmegebühren (Preise inkl. Mwst)

niedergelassene Tierärzte

$390 €$

Assistenztierärzte

$260 €$

Studenten und Tierärzte im Ruhestand

$130 €$

Information und Anmeldung

Pferdeheilkunde Curriculum, Postfach 0805 39, 10005 Berlin

Tel: 017623411422 Fax: 03028040452

E-Mail:berlin@pferdeheilkunde.de www.pferdeheilkunde.de 
trolled increased exercise program based on sequential ultrasound examinations and patience seems to be important in treating tendonitis and probably might be beneficial for this problem as well. Furthermore additional treatments, like intralesional injections of stemcells and growth factors might be considered (see discussion).

\section{Primary lesion 2: Desmitis of the collateral ligament of the distal interphalangeal (DIP) joint}

The collateral ligaments (CLs) of the distal interphalangeal (DIP) joint originate from depressions on the distal medial and lateral aspects of the middle phalanx. They insert both in small depressions on the dorsomedial and dorsolateral aspects of the distal phalanx, close to the joint margins, and to the dorsal aspect of the medial and lateral cartilages of the foot (Budras and Röck 2004). The clinical signs of desmitis of the collateral ligament do not differ from the classical signs of navicular disease. A palmar digital nerve block of the limb reduces lameness remarkably (in 70\% of the cases) and abaxial sesamoid nerve blocks abolish lameness (Dyson and Murray 2004). Radiographs of the navicular bones are classified as 2 and not considered the major cause of the lameness. Before desentisising the DIP joint and bursa, the intra-articular/thecal pressure can be measured, using a pressure transducers attached to a 22 gauge needle, while the horse stands squarely (Zuther and Hertsch 2004). An increased pressure is measured in the DIP joint and not in the bursa. The intra-articular anaesthesia of the DIP joint reduces the lameness not more than $30 \%$, which can be explained by its extra-articular anatomic location (Dyson and Murray 2004). Intrabursal analgesia is negative. A unilateral nerve block of the digital palmar nerve gives the same result as the bilateral nerve block.

With the advent of diagnostic ultrasonography and MRI it has become possible to evaluate the collateral ligaments (Grewal et al. 2004, Busoni and Denoix 2001, Turner and Sage 2002, Dyson and Murray 2004, Whitcomb 2005, Zubrod et al. 2005 ). However ultrasonographic abnormalities of the $\mathrm{CL}$ are identified in only 32\% horses (Dyson and Murray 2004). The medial collateral ligaments are mostly involved (74\% Dyson and Murray 2004). With ultrasonography the collateral ligament can be subtle enlarged with a mild decrease in echogenity to more severe lesions. Commonly a mild distension of the DIP joint capsule is observed. MRI reveales an alteration in size and signal in the $\mathrm{CL}$ with a distension of the DIP.

By identifying the lesions the prognosis is adapted. Follow-up information available to date indicates that the prognosis for full functional recovery is guarded, with only $29 \%$ of horses with primary collateral desmitis resuming full athletic function (Dyson et al. 2005).

An extended resting period with a progressive excercise program seems to be indicated. Corrective trimming and shoeing is important to prevent asymmetric foot placement due to different heights in the quarters causing rotation and sliding of the distal phalanx and consequently stress on the ligaments. Whether with this particular diagnosis elevation of the heel should be effective is not studied, and an egg bar shoe or reverse shoes with a rounded toe supports the heel causing increased interphalangeal joint flexion and fetlock extension might not be recommended (Denoix et al. 2005). The objec- tive of the shoeing for collateral ligament injuries is to reduce tension of the injured structure. For an injury of the medial collateral ligament the corrective shoeing could additionally consists in providing more support (wider branch) on the side of the lesion, with improved rolling effect on the opposite (lateral) side. The reverse is recommanded for lateral collateral injuries (Denoix et al. 2005). Shockwave therapy might be considered to improve neovascularisation of the collateral ligament (Bär et al. 2001, Caminoto et al. 2005, Kersh et al. 2006). Another possibility might be in case of a core lesion the injection of stem cells under ultrasonopgraphy guidance in combination with growth factors, and bioresorbable polymers (Smith et al. 2003, Smith et al. 2006). In case of distension of the DIP joint and a suspected associated synovitis intra-articular treatment of the DIP joint with short acting corticosteroids might be considered to reduce the inflammatory reaction, and consequently the intra-articular pressure. Care must be taken not to interfere with the treatment of the desmitis whereas corticosteroids might act contradictionaly. The reconvalescense should be controlled by ultrasonography. The additional reveries for tendonitis (see discussion) might improve healing with the desmitis as well. Intralesional injection under ultrasonography guidance is certainly possible.

\section{Primary lesion 3. Desmitis of the impar ligament}

The impar ligament originates from the navicular bone and inserts to the distal phalanx. It forms a part of the podotrochlea and thus was considered as a possible cause of lameness in horses with the clinical signs of navicular disease without any radiological abnormalities in the navicular bone. Again no specific clinical finding can be made. Perineural anaesthesia abolishes lameness as well as an intra-articular DIP joint and an intra-thecal bursa analgesia.

With ultrasonography per transcutaneal approach indications of changes can be obtained (Bursoni and Denoix 2004), however with the MRI diagnosis can be made by the recognision of ligament swelling/thickening, irregularity at the palmar border and abnormal adherence to the DDFT, entesophyte formation at its insertion, strands to the navicular bursa and complete disruption (Murray et al 2006).

When a desmitis of the impar ligament is diagnosed a prolonged resting period of 3-6 months with hand walking exercise is advised. Besides that corrective trimming and orthopaedic shoeing (wedge and rounded toe) could be helpful in reducing the pressure on the ligament, based on the same principles as described for the tendonitis of the DDFT. Also intralesional injections might be beneficial.

Even the horse might benefit of arthroscopic debridement of the impar ligament and creating a connection between the DIP joint and the bursa analog to the treatment of desmitis of the intersesamoidean ligament and axial ostitis of the proximal sesamoid bones (Dabareiner et al 2001). However, the prognosis is not favourable.

\section{Primary lesion 4: Desmitis of the medial straight sesa- moidean ligament}

Desmitis of the SSL proximal to its insertion on the middle phalanx or more proximally should be considered as a possible 
cause of lameness in horses with palmar foot pain and no radiological abnormalities (Schneider et al. 2003). The straight sesamoidean ligament originate from the base of the proximal sesamoid bones and the intersesamoidean ligament. and insert at the proximal eminence of the middle phalanx (Budras and Röck 2004). The clinical signs fit in the palmar foot syndrome. Pressure between the bulbs gives a pain reaction and the pastern region gives the impression of being slightly thickened. A palmar nerve block diminishes lameness with $60 \%$ and an abaxial nerv block abolishes lameness. Intra-articular analgesia of the DIP joint is negative and of the proximal interphalangeal joint diminishes lameness with $40 \%$. Ultrasonography of the palmar aspect of the pastern reveales a thickening of the straight sesamoidean ligament with a hypoechogenity areas like in the distocentral part of the ligament. However, ultrasonography of the straight sesamoidean ligaments can be difficult to perform and interpret (Rantanen and McKinnon 1998, Schneider et al. 2003, Reef 2006). A hypoechoic area in the distal part of the straight sesamoidean ligaments is seen in normal horses and might be easily misinterpreted as pathological finding (Reef and Genovese 2003, Rantanen and McKinnon 1998, Schneider et al. 2003). To ensure the diagnosis a MRI will be helpful in assessing the lesions in and around the ligament. Whereas most of the time the cause seems to be trauma changes at its origin and insertion might occur, like fragmentation and subchondral cystic like lesions of the proximal eminence of the second phalanx.

Knowing these lesions changes the treatment compared to the past. With a prolonged resting period (3-6 months) followed by progressive exercise program under ultrasonographic control the prognosis is favourable (Schneider et al. 2003, Brünott et al. 2006). Also for recent injuries of distal sesamoidean ligaments, rolling egg-bar type shoes or elevation of the heels are unappropriate (Denoix et al. 2005). This type of shoe would increase the stresses on the weakened tendon. A flat and thin shoe with a wide toe and narrow heels is indicated in order to limit the DIPJ flexion. This shoe is indicated to place more stresses on the DDFT in order to support the fetlock and remove tension in the SDFT and suspensory apparatus. It should be maintained during 2 shoeing periods ( 0 to 3 months after the initial injury) after which an elevation of the heels might be considered to lengthened the injured ligaments (Denoix et 2005).

In case of desmitis of the straight sesamoidean ligament ultrasonography is indicative for the diagnosis. CT and MRI images specify the bony changes and the severity of the desmitis. It leeds to an adjusted treatment and reoccurrence of the lesion could be prevented.

\section{Discussion}

With the gained knowledge of the underlying cause of the lameness by using the diagnostic imaging techniques it became possible to adapt treatment and prognosis. Certainly it does not change the approach to all different entities, like for the horse with changes within the navicular bone or combination of changes; then the prognosis remains still guarded till poor. However, if the diagnosis is synovitis of the DIP joint or bursa intra-articular treatment is indicated. With lesions in the deep digital flexor tendon, collateral ligament, distal annular ligament, the straight sesamoidean ligament or impar ligament a prolonged resting period and progressive increasing training advise might improve prognosis. Also the recent biomechanicals studies make it possible to academically support the orthopaedic shoeing. There fore it is no longer just a palmar foot syndrome, but a lameness with an identified primary lesion, creating the possibility to specify treatment and improving the prognosis.

Most soft-tissue injuries continue to require 6-12 months of rest before return to competition, depending on the severity of the original lesion and the speed with which an individual horse may repair the damage. A hasty return to full exercise significantly increases the risk of reinjury after sustained competition.

\section{Does the obtained knowledge change treatment}

For most veterinarians, therapeutic strategies for navicular disease incorporate a reduction in load-bearing by some type of corrective shoeing and controlled exercise; in the past this was based on empirical findings, but is now supported by scientific studies. That shoeing is effective in changing the forces was confirmed by the finding that horses shod with flat shoes had a higher maximal force exerted on the navicular bone by the DDFT than non-shod horses (Willemen et al. 1999, Wilson et al 2001). The effect of elevation of the heels has been explained with primary lesion 1 tendonitis of the DDFT. Whether the results of the studies can be generated to the clinical situation and how this influences horses with navicular disease is not known.

Studies on the effect of an egg-bar shoe are controversial. Egg-bar shoes, as introduced by Ostblom et al. (1984), have no effect on the forces acting on the navicular bone in sound horses (Willemen et al. 1999). However, in some horses with navicular disease and collapsed heels, the force was decreased (Wilson et al. 2001). Further support for the efficacy of the egg-bar shoe was produced by a recent study which revealed that the effective increase in the length of the toe-heel axis caused the centre of pressure to shift caudally, thereby decreasing the moment arm of the DIP and reducing the pressure on the navicular bone (Rogers and Back 2003).

With the natural balance shoe, or by pulling the toe of the shoe back, the breakover of the stride starts earlier, although the load on the navicular bone at the moment of breakover is increased (Wilson et al. 2001, Eliashar et al. 2002, Eliashar et al. 2004). The use of natural balance shoes does not, however, reduce the peak DIP joint moment or the force on the navicular bone.

Experimental studies help to understand why a specific shoe might be beneficial. However, similar studies still need to be performed in horses with clinical problems, different hoof conformations and on various surfaces.

Supportive medical treatment has not changed much over the years. NSAIDs such as phenylbutazone are used to break the pain cycle or maintain normal daily function, although the risk is that, once the pain has been relieved, excessive mechanical loading on the navicular bone area might accelerate the progress of pathology. Flunixin meglumine and phenylbutazone appear to have similar analgesic effects in horses with navicular disease (Erkert et al. 2005). Intra-articular or intrabursal injec- 
tion of corticosteroids with or without hyaluronic acid (Ackermann et al. 1977, Dietz and Wiesner 1982, Turner 1989, Turner and Tucker 1989, Verschooten et al. 1990) is optional, certainly in those cases with a distended synovial cavity.

A more physical non-invasive treatment is extracorporeal shock wave therapy (Bär et al. 2001, Blum 2004, McClure et al. 2004), which has been shown to stimulate neovascularisation of the bone-tendon junction (Wang et al. 2003). Extracorporeal shock waves are acoustic pressure gradient waves. Wave energy is released at interfaces of tissues that have different acoustic impedances and results in compression and shear loads on the surface of the material with the greater impedance. The application of shockwaves through the bulbs of the heel proved to be more effective than applying shokkwaves through the frog region of the sole (Blum 2004). Treatment with ESW also results in a transient analgesic effect, caused by damage to peripheral nerves that results in slower nerve conduction and, presumably, impaired perception of peripheral pain (Bolt et al. 2004). It is, however, still not clear what is responsible for the beneficial effects of ESW.

More reveries concerning possibilities in treatment are based on the current new technologies of regenerative medicine. With the lesion in the tendons and ligaments (Lig. impar, collaterals and straight sesamoidean ligament) an intralesional treatment with hyaluronan, beta aminoproprionitrile fumarate (BAPN) or polysulphated glycosaminoglycans (PSGAG) or systemic administration of PSGAG could be optional (Dyson 2004, Yagishita et al. 2005). However new developments in treating tendon lesions consists of intralesional injections of mesenchymal cells (MSC), or a extracellular matrix as natural scaffold (ACell Vet Powder) (Herthel 2001, Smith et al. 2003, Smith 2004, Smith et al. 2006, Mitchell 2006). The MSC's can be obtained of embryonic cell, bone marrow or adiposederived adult stem cells. MSCs injected into an area of damaged tendon might differentiate into mature tendon (or ligament) fibroblasts under the signaling influences of the tissue and produce the appropriate matrix products for repair. The MSCs obtained from bone marrow may be isolated, expanded in culture in the laboratory, suspended in $1 \mathrm{ml}$ of bone-marrow supernatant, and injected into the tendon lesion several weeks later. The availability of autologous MSCs from a readily accessible source within a 48-h period is the advantage of the adipose-derived adult stem cells that are currently being marketed commercially for the veterinary market (Dahlgren ef al 2005). It is also possible to inject bone marrow itself, immediately after collecting. Bone marrow contains MSC, high concentrations of growth factors, and perhaps other up till now unknown stimulating factors. Bone marrow might even function as good as all the very specific expanded cells, due to the combination of factors. Several growth factors have been shown to improve the healing of tendons and ligaments in a variety of models. Growth factors are peptide-signaling molecules that regulate cellular metabolism. Growth factors enhance tendon and ligament healing by increasing ECM synthesis to promote cell proliferation and differentiation and by stimulating vascular ingrowth. Exogenous treatment with insulin-like growth factor-I (IGF-I) within the first 2 to 4 weeks after tendon injury may bolster the meager PDGF paracrine-autocrine intrinsic response to injury and may facilitate an improved return to sustained athletic function (Dalgren et al. 2002, Dalgren et al. 2006, Donnelly et al. 2006) .
With the Acell, an extracellular matrix, a xenogeneic product, is injected. Histopathology in species other than the equine have indicated a profound angiogenic response developing in the first 5-7 days post treatment. Accompanying this response is the recruitment of bone marrow-derived mesenchymals cells into the treated tissue, thus stimulating healing (Mitchell 2004).

The intralesional injection can be done using ultrasonography guidens or the use of CT as an interventional tool to image a metallic needle and guidance the needle to its location (Puchalski et al 2005). The results obtained by intralesional treatment are anecdotical and needs further investigation but are promising.

Another additional treatment is the use of swim therapy and hyperbaric oxygen therapy as potential adjuncts. Hyperbaric oxygen therapy may increase collagen synthesis and collagen crosslink formation during the early healing process (Hsu et al. 2004).

Treatment by use of pulsed magnetic fields system has been used to accelerate wound healing and soft tissue swelling. It induces an electrical field within the tendon. This induced electrical field is thought to influence the healing process by affecting the inflammatory cells that line the tendon sheath. (Owegi and Johnson 2006). Ultrasound guided electro-coagulation has been used in human to reduce tendonvascularity and thereby reducing pain from the chronic tendonitis (Boesen et al. 2006).

An alternative interesting treatment might be surgical debridement. Dabareiner et al. (2001) gained positive results by arthroscopic debridement of the intersesamoidean ligament and the abaxial site of the proximal sesamoid bones in case of desmitis of the intersesamoidean ligament and axial ostitis of the proximal sesamoid bones. The results in the described cases was surprisingly positive and might be an idea for the horses with palmar foor syndrome due to a desmitis if the impar ligament. An arthroscopic debridement of the impar ligament and the creation a connection between the DIP joint and the bursa analog to that treatment could perhaps be a solution. However, up to now, the prognosis is not favourable.

\section{What will the future bring in diagnostics?}

During the early part of the 21 st century, researchers made substantial advances in the identification and validation of biomarkers for joint damage. Remarkable progress has been made in the study of molecular mechanisms involved in degenerative joint disease. Mechanical loading triggers a cascade of molecular events that may lead to disease in susceptible individuals. These events involve the production or release of free radicals, cytokines, fatty acid catabolites, neuropeptides, and matrix-degrading enzymes. Under normal circumstances, these molecules may be involved in the remodelling of articular and subchondral tissues in response to changing functional demands. However, if those functional demands exceed the adaptive capacity of the joint of an individual horse, then pathology will develop and a change in pattern of the biomarkers will be detectable.

In horses suffering clinically from 'navicular disease', changes in biochemical markers have been observed in the DIP and 
the navicular bursa: these include, a decrease in glycosaminoglycan concentrations (GAG), lower GAG/cartilage oligomeric matrix protein (COMP) ratios, increased hyaluronic acid $(H A)$ and relative increase in the activity of the matrix metalloproteinisaes, MMP-2 and MMP-9 (Viitanen et al 2001). When interpreting the results, it should be taken in account that the markers are an expression of active processes, and that accumulated damage over time may not be reflected by the current activity of the disease (van den Boom et al 2004). Moreover, the reliability of synovial fluid biomarkers for indicating pathology in any given joint has not yet been confirmed and, therefore, biomarker assays are not yet ready for clinical use. Nevertheless, a combination of repeated measurement of selected markers with other diagnostic techniques (Mcllwraith 2005) shows promise for allowing a good assessment of the condition of a joint.

In conclusion the change in our approach to the interpretation of diagnostic analgesia, together with new diagnostic imaging techniques, biomarkers and new information about the biomechanics of the navicular area, gradually proved that the navicular bone was indeed not the only structure causing the clinical signs. Other primary lesions can be responsible for the lameness, thus creating the possibility to adapt treatment end adjust prognosis. Clear is the optimal treatment and prognosis differ per pathological entity. This probability was emphasised by Dyson et al (2005), who recorded differences in prognosis; primary soft tissue injuries were associated with a guarded prognosis for return to full athletic function, and lesions in the navicular bone per se with a poor prognosis. The diversity in pathology and anatomical extent of the disease, as identified using MRI, offers the opportunity to target the treatment plan to the lesion found. Unloading the heel seems to be necessary in the case of palmar foot problems, while the nature of additional supportive treatment varies depending on the underlying disorder. A primary tendon lesion or collateral desmitis might be helped by a prolonged period of controlled exercise combined with corrective shoeing, NSAIDs and even stem-cell therapy, whereas lesions within the navicular bone might benefit from a different combination of treatments. Double-blind, controlled studies are required to confirm the effect of specific treatments on specific primary lesions. Knowing the primary cause of palmar foot syndrome offers a lot of opportunities in treating and improving the prognosis.

\section{References}

Ackermann N., Johnson J. and Dorn C. R. (1977): Navicular Disease in the Horse: Risk Factors, radiographic changes, and response to therapy. J Am Vet Med Assoc 170,183187

Bär K., Weiler M., Bodamer J., Rupprecht H., Schramm M. and Carbon R. (2001): Extrakorporale Stoßwellentherapie (ESWT)- eine Möglichkeit zur Therapie der Podotrochlose. Extracorporeal shock wave therapy-a remedial procedure for navicular disease. Tierärztliche Praxis Grosstiere 29, 163-167

Boesen M. I., Torp-Pedersen S., Koenig M. J., Christensen R., Langberg H., Holmich P., Nielsen M. B. and Bliddal H. (2006): Ultrasound guided electro-coagulation in patients with chronic non-insertional Achilles tendinopathy: a pilot study. Br J Sports Med. Jun 28

Boom van den R. (2004): Synovial fluid as a mirror of equine joint (patho)physiology. Thesis Utrecht University.
Bolt D. M., Burba D. J., Hubert J. D., Strain G. M., Hosgood G. L., Henk W. G. and Cho D. Y. (2004): Determination of functional and morphologic changes in palmar digital nerves after nonfocused extracorporeal shock wave treatment in horses. Am J Vet Res. 65, 1714-1718

Blum N. (2004) Justus-Liebig-Universität Giessen Dissertation ISBN/ ISSN3-89687-675-9 Wettenberg: WB Laufersweiler 2,

Budras K.-D. und Röck (2004): Atlas der Anatomie des Pferdes, Budras und Röck ISBN 3899930029

Busoni V. and Denoix J. M. (2001): Ultrasonography of the podotrochlear apparatus in the horse using a transcuneal approach: technique and reference images. Vet Radiol. Ultrasound 42, 534-40.

Busoni V., Heimann M., Trenteseaux J., Snaps F. and Dondelinger R. F. (2005): Magnetic resonance imaging findings in the equine deep digital flexor tendon and distal sesamoid bone in advanced navicular disease - an ex vivo study. Vet Radiol Ultrasound. 46, 279-286

Chateau H., Deguerce C. and Denoix J. M. (2005): Three-dimensional kinematics of the equine distal forelimb: effects of a sharp turn at the walk Equine Vet J 37, 12-18

Dabareiner R. M., Watkins J. P., Carter G. K., Honnas C. M. and Eastman T. (2001): Osteitis of the axial border of the proximal sesamoid bones in horses: eight cases (1993-1999). J Am Vet Med Assoc 219, 82-86

Dahlgren L. A., van der Meulen M. C., Bertram J. E., Starrak G. S. and Nixon A. J. (2002): Insulin-like growth factor-I improves cellular and molecular aspects of healing in a collagenase-induced model of flexor tendonitis. J Orthop Res 20, 910-919

Dahlgren L. A., Haupt J. L., Yeager A. E. et al. (2005): Adipose-derived adult stem cells: a preliminary investigation in a collagenase model of tendonitis. J Am Vet Med Assoc 2005 (in press)

Dahlgren L. A., Mohammed H. O. and Nixon A. J. (2006): Expression of insulin-like growth factor binding proteins in healing tendon lesions. J Orthop Res. 24, 183-192

Dietz O. and Wiesner E. (1982): Handbuch der Pferdekrankheiten für Wissenschaft und Praxis. Verlag S. Karger, Berlin

Denoix J. M. (1999): Functional anatomy of the equine interphalangeal joints. Proc Amer.Assoc. Equine Pract. 45, 174-177

Denoix J.-M., Crevier-Denoix N. and Château H. (2005): Corrective Shoeing of Equine Distal Limb Injuries. In: Chuit P. and Montavon S. (Eds.), 9th Congress on Equine Medicine \& Surgery in Geneva. Ithaca: International Veterinary Information Service (www.ivis.org), Document No. P1918.1205.

Dyson S. J. and Kidd L. (1993): A comparison of responses to analgesia of the navicular bursa and intra-articular analgesia of the distal interphalangeal joint in 59 horses. Equine Vet J. 25, 93-98

Dyson S., Murray R., Schramme M. and Branch M. (2003a): Magnetic resonance imaging of the equine foot: 15 horses. Equine Vet J. 35, 18-22

Dyson S., Murray R., Schramme M. and Branch M. (2003b): Lameness in 46 horses associated with deep digital flexor tendonitis in the digit: diagnosis confirmed with magnetic resonance imaging. Equine Vet J. 35, 681-690

Dyson S. J. (2004): Medical management of superficial digital flexor tendonitis: a comparative study in 219 horses (1992-2000). Equine Vet J. 36, 415-419

Dyson S. J. and Murray R. (2004): Collateral Desmitis of the Interphalangeal Joint in 62 Horses (January 2001 -December2003). In: (Ed.), 50 th Annual Convention of the American Association of Equine Practitioners, 2004 - Denver, CO, USA. Ithaca: International Veterinary Information Service (www.ivis.org; Document No. P1436.1204.)

Dyson S. J., Murray R. and Schramme M. C. (2005): Lameness associated with foot pain: results of magnetic resonance imaging in 199 horses (January 2001 - December 2003) and response to treatment. Equine Vet J. 37, 113-121

Donnelly B. P., Nixon A. J., Haupt J. L. and Dahlgren L. A. (2006): Nucleotide structure of equine platelet-derived growth factor-A and $-B$ and expression in horses with induced acute tendinitis. Am J Vet Res 67, 1218-1225

Eliashar E., McGuigan M. P., Rogers K. A. and Wilson A. M. (2002): A comparison of three horseshoeing styles on the kinetics of breakover in sound horses. Equine Vet J. 34, 184-190

Eliashar E., McGuigan M. P. and Wilson A. M. (2004): Relationship of foot conformation and force applied to the navicular bone of sound horses at the trot. Equine Vet J. 36, 431-435 
Erkert R. S., Macallister C. G., Payton M. E. and Clarke C. R. (2005): Use of force plate analysis to compare the analgesic effects of intravenous administration of phenylbutazone and flunixin meglumine in horses with navicular syndrome. Am J Vet Res. 66, 284-288.

Grewal J. S., McClure S. R., Booth L. C., Evans R. B. and Caston S. S. (2004): Assessment of the ultrasonographic characteristics of the podotrochlear apparatus in clinically normal horses and horses with navicular syndrome. J Am Vet Med Assoc. 225, 1881-1888

Heel van M. C. V., Barneveld A., Weeren van P. R. and Back W. (2004): Dynamic pressure measurements for the detailed study of hoof balance: the effect of trimming. Equine vet J. 36, 778-782

Herthel D. J. (2001): Enhanced suspensory ligament healing in 100 horses by stem cells and other bone marrow components. In: Proceedings of the 47th Annual American Association of Equine Practitioners Convention, 319-321

Hinterhofer C., Stanek C. and Haider H. (2000): The effect of flat horseshoes, raised heels and lowered heels on the biomechanics of the equine hoof assessed by finite element analysis (FEA). J Vet Med A Physiol Pathol Clin Med. 47, 73-82

Hsu R. W., Hsu W. H., Tai C. L. and Lee K. F. (2004): Effect of hyperbaric oxygen therapy on patellar tendinopathy in a rabbit model.J Trauma. 57, 1060-1064

Kersh D. K., McClure R. S., Van Sickle D. and Evans B. R. (2006): The evaluation of extracorporeal shock wave therapy on collagenase induced superficial digital flexor tendonitis. Vet Comp Orthop Traumatol. 19,99-105

Mair T. S. and Kinns J. (2005): Deep digital flexor tendonitis in the equine foot diagnosed by low-field magnetic resonance imaging in the standing patient: 18 cases Vet Radiol Ultrasound. 46, 45866

McClure S., Evans R. B., Miles K. G., Reinertson E. L., Hawkins J. F. and Honnas C. M. (2004): Extracorporeal shock wave therapy for treatment of navicular syndrome. In: (Ed.), 2004 - Denver, CO, USA. Ithaca: International Veterinary Information Service (www.ivis.org), 2004; Document No. P1452.1204

Mitchell R. D. (2004): Treatment of tendon and ligament injuries with UBM powder (ACell-Vet). In: Proceedings of the 14th Am Coll Vet Surg Symp, 190-193

Murray R. C., Blunden T. S., Schramme M. C. and Dyson S. J. (2006): How does magnetic resonance imaging represent histologic findings in the equine digit? Vet Radiol Ultrasound. Jan-Feb 47, 17-31

Ostblom L., Lund C. und Melsen F. (1984): Navicular bone disease: results of treatment using egg-bar shoeing technique. Equine Vet J. 16, 203-206

Owegi R. and Johnson M. T. (2006): Localized pulsed magnetic fields for tendonitis therapy. Biomed Sci Instrum. 42, 428-433

Puchalski S. M., Snyder J. R., Hornof W. J., MacDonald M.H. and Galuppo L. D. (2005): Contrast-Enhanced Computed Tomography of the Equine Distal Extremity. In: (Ed.), 51 Annual Convention of the American Association of Equine Practitioners - AAEP, 2005 - Seattle, WA, USA. Ithaca: International Veterinary Information Service (www.ivis.org), 2005; Document No. P2670.1205

Rantanen N. W. and McKinnon A. O. (1998): Equine diagnostic ultrasonography. Baltimore, MD:Williams \& Wilkins

Rijkenhuizen A. B. M. (2006): Navicular disease: a review of what's new. Equine Vet J. 38, 82-88

Rogers C. W. and Back W. (2003): Wedge and eggbar shoes change the pressure distribution under the hoof of the forelimb in the square standing horse. J. of Equine Science, 23, 306-309

Smith R. K., Korda M., Blunn G. W. and Goodship A. E. (2003): Isolation and implantation of autologous equine mesenchymal stem cells from bone marrow into the superficial digital flexor tendon as a potential novel treatment.Equine Vet J. 35, 99-102

Scheffer C. J. and W. Back (2001): Effects of 'navicular' shoeing on equine distal forelimb kinematics on different track surface. Veterinary Quarterly 23, 191-195

Schoonover M. J., Jann H. W. and Blaik M. A. (2005): Quantitative comparison of three commonly used treatments for navicular syndrome in horses. Am J Vet Res. 66, 1247-1251

Reef V. B. (2006): Tendon and ligament ultrasonography in the pastern. 12th Congress SIVA, Multisala, Bologna
Schneider R. K., Gavin P. R. and Tucker R. L. (2003): What MRI is Teaching us about Navicular Disease. In: 49th Annual Convention of the American Association of Equine Practitioners. Internet Publisher: International Veterinary Information Service, Ithaca NY (www.ivis.org), 2003

Smith R. K., Korda M., Blunn G. W. and Goodship A. E. (2003): Isolation and implantation of autologous equine mesenchymal stem cells from bone marrow into the superficial digital flexor tendon as a potential novel treatment. Equine Vet J. 35, 99-102

Smith J. J., Ross M. W. and Smith R. K. (2006): Anabolic effects of acellular bone marrow, platelet rich plasma, and serum on equine suspensory ligament fibroblasts in vitro. Vet Comp Orthop Traumatol. 19, 43-47

Smith R. K. W. (2004): Stem cell therapy for tendon and ligament injuries- Clinical results. Proceedings 12th ESVOT Congress, Munich, 187-189

Turner A. S. and Tucker C. M. (1989): The evaluation of isoxsuprine hydrochloride for the treatment of navicular disease: a double blind study. Equine Vet J. 21, 338-341

Turner T. A. (1989): Diagnosis and treatment of the navicular syndrome in horses. Vet Clin North Am Equine Pract. 5, 131-44 Review.

Turner T. and Sage A. (2002): Desmitis of the distal interphalangeal collateral ligaments: 22 cases. In: Proceedings of the 48th Annual American Association of Equine Practitioners Convention, 343-346

Verschooten F., Desmet, P., Peremans K. and Picavet T. (1990): Navicular disease in the horse: the effect of controlled intra-bursal corticoid injection. J Equine Vet Sci 4, 316-320

Viitanen M., Bird J., Makela O., Schramme M., Smith R., Tulamo R. M. and May S. (2001): Synovial fluid studies in navicular disease.Res Vet Sci. 71, 201-206

Wang C. J., Wang F. S., Yang K. D., Weng L. H., Hsu C. C., Huang C. S. and Yang L. C. (2003): Shock wave therapy induces neovascularization at the tendon-bone junction. A study in rabbits. J Orthop Res. 21, 984-989

Willemen M. A., Savelberg H. H. and Barneveld A. (1999): The effect of orthopaedic shoeing on the force exerted by the deep digital flexor tendon on the navicular bone in horses. Equine Vet J. 31, 25-30

Wilson A. M., McGuigan M. P., Fouracre L. and MacMahon L. (2001): The force and contact stress on the navicular bone during trot locomotion in sound horses and horses with navicular disease. Equine Vet J. 33, 159-165

Whitcomb M. B. (2006): How to Perform a Complete Ultrasonographic Evaluation of the Pastern. In: (Ed.), 51 Annual Convention of the American Association of Equine Practitioners - AAEP, 2005 Seattle, WA, USA. Ithaca: International Veterinary Information Service (www.ivis.org), 2006; Document No. P2681.1205

Yagishita K., Sekiya I., Sakaguchi Y., Shinomiya K. and Muneta T. (2005): The effect of hyaluronan on tendon healing in rabbits. Arthroscopy. 21, 1330-1336

Zubrod C. J., Farnsworth K. D., Tucker R. L. and Ragle C. A. (2005): Injury of the collateral ligaments of the distal interphalangeal joint diagnosed by magnetic resonance. Vet Radiol Ultrasound. 46, 11-16

Zuther M. and Hertsch B. (2004): Zur Differenzierung des Podotrochlose-Syndroms mit Hilfe von diagnostischen Anästhesien und der Druckmessung in Hufgelenk und Bursa podotrochlearis. Pferdeheilkunde 20, 525-532

Dr. Astrid B.M. Rijkenhuizen, DVM, PhD, Dipl. ECVS

Department of Equine Sciences

Faculty of Veterinary Medicine

Utrecht University

Yalelaan 12,

3584 CM Utrecht

The Netherlands

a.riikenhuizen@vet.uu.nl 